\title{
INFECÇÃO DO TRATO URINÁRIO NA GESTAÇÃO: CONTEXTO SOCIAL E CARACTERÍSTICAS CLÍNICAS
}

\section{ARTIGO ORIGINAL}

RUBEL, Rosália ${ }^{1}$, SILVA, Otília Beatriz Maciel da², GREIN, Fernanda Pereira Lopes ${ }^{3}$, MUGGIATI, Mario Augusto ${ }^{4}$, SALOMÃO, Renan Ishikawa ${ }^{5}$, ROCHA, Denise Jorge Munhoz da ${ }^{6}$, SENESI, Lenira Gaede ${ }^{7}$

RUBEL, Rosália. Infecção do trato urinário na gestação: contexto social e características clínicas. Revista Científica Multidisciplinar Núcleo do Conhecimento. Ano. 06, Ed. 11, Vol. 01, pp. 80-98. Novembro 2021. ISSN: 2448-0959, Link de acesso: https://www.nucleodoconhecimento.com.br/saude/caracteristicas-clinicas

\section{RESUMO}

Um dos Objetivos de Desenvolvimento do Milênio (ODM) estabelecidos pela ORGANIZAÇÃO DAS NAÇÕES UNIDAS em 2015 é reduzir a mortalidade materna, até 2030, para 30 óbitos para cada 100 mil nascidos vivos. Infecções do trato urinário (ITU) na gestação estão entre as principais causas de complicações e frequentemente cursam para o agravamento do quadro clínico materno-infantil. Conhecer o contexto social e as características clínico-laboratoriais das gestantes com ITU é importante para a elaboração de protocolos de cuidado diferenciados e para o sucesso terapêutico. Método: A presente pesquisa delineou o perfil sociodemográfico, epidemiológico e clínico-laboratorial de gestantes internadas em uma maternidade pública de baixo risco, para tratamento de ITU, através da análise documental de 95 prontuários, no período de janeiro a dezembro de 2019. Resultados: As pacientes

\footnotetext{
${ }^{1}$ Doutora em Processos Biotecnológicos - Universidade Federal do Paraná (UFPR), Mestra em Biologia Celular UFPR, Especialista em Bacteriologia - UFPR, Farmacêutica-Bioquímica - UFPR. ORCID: https://orcid.org/00000003-1178-4333.

${ }^{2}$ Enfermeira. Mestre e Doutora em Enfermagem. ORCID: https://orcid.org/0000-0002-1541-5618.

${ }^{3}$ Enfermeira, Especialista em Controle de Infecção Hospitalar.ORCID: https://orcid.org/0000-0003-2107-700x.

${ }^{4}$ Médico Obstetra. ORCID: https://orcid.org/0000-0002-0758-7487.

${ }^{5}$ Engenheiro Químico. ORCID: https://orcid.org/0000-0002-2245-3575.

${ }^{6}$ Enfermeira, Mestre em Enfermagem. ORCID: https://orcid.org/0000-0002-2385-2391.

${ }^{7}$ Médica Obstetra, Mestrado em Medicina (Tocoginecologia). ORCID: https:/orcid.org/0000-0001-7786-3523. RC: 100422

Link de acesso: https://www.nucleodoconhecimento.com.br/saude/caracteristicas-clinicas
} 
adolescentes (entre 15 e 19 anos) foram $24,21 \%$ do total, enquanto $71,58 \%$ tinham entre 20 e 34 anos. Pacientes que não concluíram o primeiro grau foram 17\%, aquelas que ultrapassaram o segundo grau foram $39 \%$. Apenas $2,11 \%$ tinham curso superior completo. Gestantes primigestas foram $28,42 \%$ dos casos. A maioria das gestantes $(91,58 \%)$ estava no segundo $(45,26 \%)$ e no terceiro $(46,32 \%)$ trimestres. O tempo médio de internação foi entre três e oito dias. Mais da metade das mulheres $(51,57 \%)$ precisou de mais de uma internação hospitalar, sendo que dessas, 37,89\% estavam na segunda e $13,68 \%$ na terceira internação, pelo mesmo motivo. O desfecho clínico majoritário foi parto vaginal $(48,4 \%)$, seguido de parto cesáreo (13,7\%). Destaca-se o histórico de infecção do trato urinário recorrente em $43 \%$ das mulheres. Conclusão: Os resultados obtidos serão úteis para fundamentar outras pesquisas e para a elaboração de protocolos institucionais com o intuito de monitorar as gestantes com infecção urinária, desde a consulta inicial na Unidade Básica de Saúde até o desfecho final na maternidade, mapeando os principais fatores de risco.

Palavras-chave: Obstetrícia, pielonefrite, cistite, morbidade.

\section{INTRODUÇÃO}

Cerca de 800 mulheres morrem diariamente no mundo em decorrência de complicações na gravidez e no parto. Para cada mulher que morre aproximadamente 20 outras sofrem sérias consequências para a sua saúde e integridade. A razão de mortalidade materna (MMR: morte por 100.000 nascidos vivos) em regiões em desenvolvimento é 14 vezes maior que em regiões desenvolvidas, ocorrendo em países pobres ou de baixa renda $94 \%$ dessas mortes maternas. Outro agravante é que gestantes adolescentes (10 a 14 anos) apresentam um risco maior de complicações e mortes em relação a mulheres adultas (ORGANIZAÇÃO PANAMERICANA DE SAÚDE, 2018).

Uma das metas dos Objetivos de Desenvolvimento do Milênio (ODM) era reduzir a RMM, até 2015 , em $75 \%$, o que corresponderia a 35 óbitos para cada 100 mil nascidos vivos (ORGANIZAÇÃO DAS NAÇÕES UNIDAS, 2000). A recente atualização das metas, lançada pela ONU em setembro de 2015, sob a ótica da sustentabilidade, RC: 100422

Link de acesso: https://www.nucleodoconhecimento.com.br/saude/caracteristicas-clinicas 
projeta uma redução da $\mathrm{RMM}$, até 2030 , para 30 óbitos para cada 100 mil nascidos vivos. Esse patamar tem sido almejado pelas nações ao redor do mundo, através da implementação de boas práticas no cuidado pré-natal, intraparto e puerpério, porém, ainda está longe de ser alcançado. No período de 2000 a 2017 a taxa global de mortalidade materna declinou 38\%, partindo de um patamar de 342 caiu para 211 mortes por 100.000 nascidos vivos. Esses dados traduzem uma taxa média anual de queda de 2,9\%, abaixo da meta estabelecida pela ONU de 6,4\% (ALKEMA, et al., 2016). No Brasil, em 2018, a RMM foi de 59,1 óbitos para cada 100 mil nascidos vivos, valores acima das metas estabelecidas pela ONU (MINISTÉRIO DA SAÚDE, 2020).

As mortes maternas ocorrem, principalmente, devido à hipertensão arterial, hemorragias, infecções de origem uterina/obstétrica e sepses (SAY et al., 2014; BLENCOWE et al., 2016; PFITSCHER et al., 2016).

Infecções do trato urinário (ITU) na gestação estão entre as principais causas de sepses, contribuindo substancialmente para a morbimortalidade materna, a prematuridade e o óbito fetal (OUD, 2014).

As infecções do trato urinário são decorrentes da presença de microrganismos que podem causar desde uma simples colonização, caracterizando o quadro de bacteriúria assintomática (BA), até infecções sintomáticas que comprometem a bexiga (cistite) e infecções renais, configurando a pielonefrite aguda. Na BA a sintomatologia clínica não se manifesta e a infecção só é detectada através de urocultura, com isolamento de um único germe em contagens superiores a 100.000 unidades formadoras de colônia colônias por mililitro de urina $(\mathrm{UFC} / \mathrm{mL})$. Na cistite não há evidências de infecção sistêmica e as queixas mais frequentes são disúria, polaciúria, urgência miccional e dor suprapúbica. Na pielonefrite aguda ocorre comprometimento do estado geral, febre, calafrios, náuseas e dor lombar alta (sinal de Giordano positivo), constituindo uma doença grave que pode demandar internamento hospitalar para tratamento (HOOTON; GUPTA, 2019a; HOOTON; GUPTA, 2019b). A etiologia microbiana das ITU é diversa, Escherichia coli é a bactéria mais frequente, ocorrendo em cerca de 50 a $60 \%$ dos casos (FRANCESCO et al., 2007). 
Presente em até $15 \%$ das gestantes, as ITU constituem uma causa comum de complicações, agravando tanto o prognóstico materno quanto o perinatal. As mudanças anatômicas e fisiológicas do trato urinário durante o período gravídico são fatores que predispõem mulheres com bacteriúria assintomática a evoluírem para ITU sintomática. O relaxamento da musculatura e a subsequente dilatação uretral que acompanha a gravidez são agentes facilitadores para a ascensão de microrganismos da microbiota genital para o trato urinário alto, resultando em maior propensão para a ocorrência de pielonefrite aguda (DUARTE et al., 2008). A imunossupressão na gravidez pode contribuir para maior morbidade, como exemplo, os baixos níveis de interleucina-6 nas mucosas e de anticorpos séricos contra antígenos de E. coli (PETERSON, et al.,1994). A incidência de BA em gestantes é aproximadamente a mesma que em mulheres não grávidas, de 2 a 10\%, entretanto, a recorrência é mais comum durante a gravidez. Caso não sejam tratadas adequadamente, em torno de $30 \%$ podem evoluir para pielonefrite aguda (MOORE, et al., 2018).

Adicionalmente, a incidência de pielonefrite aguda é mais alta em gestantes que na população em geral, provavelmente como resultado de mudanças fisiológicas no trato urinário durante a gravidez. ITU na gestação é frequentemente associada a complicações como aborto, rotura prematura de membranas, prematuridade, baixo peso ao nascer, infecção neonatal, corioamnionite, bacteremia, septicemia e choque séptico (GUPTA; HOOTON; NABER, 2011). Gestantes com suspeita de ITU devem ser monitoradas continuamente em busca de sinais indicativos da necessidade de encaminhamento a serviços de urgência ou emergência obstétrica, evitando complicações no período gestacional. O controle do quadro infeccioso depende de um diagnóstico precoce e de uma terapêutica imediata, antes da confirmação laboratorial por cultura de urina e antibiograma (SMAILL; VASQUEZ, 2015).

Entre os indicadores de acesso da mulher aos cuidados de saúde, a mortalidade materna é considerada um dos principais e o sistema de saúde deve ser capaz de responder prontamente a esta demanda (MINISTÉRIO DA SAÚDE, 2020). O desafio está em propiciar à gestante um tratamento eficaz, considerando ainda o agravante do arsenal terapêutico antimicrobiano ser restrito, devido a toxicidade de alguns fármacos para o concepto. A antibioticoterapia empírica deve ser corroborada por um RC: 100422

Link de acesso: https://www.nucleodoconhecimento.com.br/saude/caracteristicas-clinicas 
amplo conhecimento da etiologia microbiana e do perfil de suscetibilidade antimicrobiana dos microrganismos. Além dos aspectos puramente clínicos do processo saúde-doença, há que se considerar o contexto social dessas pacientes, o qual é determinante para o sucesso do tratamento. Para isso, é necessário o emprego de estratégias diferenciadas e alicerçadas no amplo conhecimento da realidade da gestante, onde equipes multiprofissionais de cuidado pré-natal atuem estabelecendo pontes com lideranças e representantes comunitários (SECRETARIA MUNICIPAL DE SAÚDE-CURITIBA, 2020). Considerando a dimensão do problema, a pergunta que direcionou esse estudo foi: Qual o contexto social e as características clínicas de gestantes internadas em uma maternidade pública de baixo risco para tratamento de ITU? Com esse objetivo, a pesquisa delineou o perfil sociodemográfico, epidemiológico e clínico-laboratorial das pacientes. O conhecimento dessa realidade permitirá a implementação de práticas de intervenção mais adequadas e seguras, assim como a elaboração de protocolos e manuais de assistência pré-natal que contemplem o conceito de ações integradas entre as equipes da atenção primária e a hospitalar.

\section{MÉTODO}

Esta é uma pesquisa observacional, descritiva e retrospectiva realizada através de um levantamento documental do banco de dados do Serviço de Controle de Infecção Hospitalar da maternidade, dados de prontuários e do sistema de informática da instituição. A amostragem incluiu 95 pacientes internadas com sinais e sintomas sugestivos de infecção urinária, ou daquelas onde a pesquisa de infecção urinária teve um caráter de exclusão para outras patologias, compreendendo o período de janeiro a dezembro de 2019. Foram excluídas da amostragem pacientes cujos prontuários estavam incompletos e com dados inconclusivos.

Foram analisadas as seguintes variáveis: a) sociodemográficas e gestacionais: idade, escolaridade, raça, idade gestacional, paridade, histórico de ITU recorrente, distrito sanitário de origem. b) clínico-laboratoriais: número de internações, tempo de internação, desfecho clínico, resultados de urocultura, uropatógenos isolados. A análise dos dados foi feita por estatística simples, as variáveis categóricas são $\mathrm{RC}: 100422$ 
apresentadas por frequência e percentual. As variáveis quantitativas são descritas por média e desvio-padrão (DP) ou por mediana e valores mínimos e máximos (mín - máx) conforme a aderência à distribuição normal.

A pesquisa foi aprovada pelo Comitê de Ética em Pesquisa com Seres Humanos do Complexo Hospital de Clínicas da Universidade Federal do Paraná (CHC-UFPR) (CAAE 26123419.4.0000.0096).

\section{RESULTADOS}

Os dados relacionados às variáveis sociodemográficas são apresentados nas tabelas 1, 2 e 3. Quanto à faixa etária, aproximadamente, a quarta parte das gestantes tinham entre 15 e 19 anos; e o maior percentual foi para a faixa entre 20 e 34 anos. Níveis de escolarização básica e média predominaram, com apenas $2 \%$ das gestantes relatando curso superior completo. Quanto ao número de gestações, aproximadamente, a terça parte das gestantes eram primigestas. Constatou-se um considerável percentual de falha no registro de paridade, o que demonstra a necessidade de uma maior integração entre as equipes do atendimento primário e terciário. A raça branca foi predominante entre as pacientes (Tabela 1).

Tabela 1. Dados demográficos de gestantes internadas em maternidade pública de baixo risco para tratamento de infecção do trato urinário. Curitiba-PR, Brasil, 2020

\begin{tabular}{|l|l|l|l|}
\hline Variáveis & N & $\%$ \\
\hline Idade (anos) & $15-19$ anos & 23 & 24,21 \\
\hline & $20-34$ anos & 68 & 71,58 \\
\hline & $35-40$ anos & 4 & 4,21 \\
\hline Escolaridade & $1^{\circ}$ Grau incompleto & 16 & 16,84 \\
\hline & $1^{\circ}$ Grau completo & 21 & 22,11 \\
\hline & $2^{\circ}$ Grau incompleto & 10 & 10,53 \\
\hline & $2^{\circ}$ Grau completo & 37 & 38,95 \\
\hline & Superior incompleto & 4 & 4,21 \\
\hline
\end{tabular}

RC: 100422

Link de acesso: https://www.nucleodoconhecimento.com.br/saude/caracteristicas-clinicas 


\begin{tabular}{|l|l|l|l|}
\hline & $\begin{array}{l}\text { Superior completo } \\
\text { Ignorado }\end{array}$ & 2 & 2,11 \\
\hline & & 5 & 5,26 \\
\hline Paridade & 1 & 27 & 28,42 \\
\hline & 2 & 10 & 10,53 \\
\hline & 3 & 10 & 10,53 \\
\hline & 4 & 7 & 7,37 \\
\hline & Não informado & 41 & 43,16 \\
\hline & & & \\
\hline Raça & Preta & 3 & 3,16 \\
\hline & Parda & 5 & 5,26 \\
\hline & Branca & 87 & 91,58 \\
\hline
\end{tabular}

$N: 95$

Fonte: Próprio autor

As pacientes atendidas na maternidade foram provenientes de diferentes Unidades Básicas de Saúde (UBS) de Curitiba, sendo que praticamente a metade dessas $(51,6 \%)$ foi encaminhada pelos Distritos Sanitários do Cajuru $(35,8 \%)$ e do Portão $(15,8 \%)$. As demais UBS apresentaram uma distribuição equitativa de referenciamento de gestantes à maternidade.

Em relação à idade gestacional, a maioria estava no segundo e terceiro trimestres. Praticamente a metade das mulheres atendidas precisou de mais de uma internação hospitalar pelo mesmo motivo. Destaca-se o histórico de ITU recorrente em considerável parcela das mulheres (Tabela 2).

Tabela 2. Características gestacionais e clínicas de gestantes com infecção de trato urinário em maternidade pública de baixo risco. Curitiba -PR, 2020

\begin{tabular}{|l|l|l|l|}
\hline Variáveis & $\mathbf{N}$ & $\%$ \\
\hline Idade gestacional (semanas) & $1^{\circ}$ trimestre $(0-13)$ & 8 & 8,42 \\
\hline & $2^{\circ}$ trimestre $(14-26)$ & 43 & 45,26 \\
\hline
\end{tabular}

RC: 100422

Link de acesso: https://www.nucleodoconhecimento.com.br/saude/caracteristicas-clinicas 


\begin{tabular}{|l|l|l|l|}
\hline & $3^{\circ}$ trimestre $(27-41)$ & 44 & 46,32 \\
\hline $\mathbf{N}^{\circ}$ de internações & & 46 & 48,42 \\
\hline & 1 & 36 & 37,89 \\
\hline & 2 & 13 & 13,68 \\
\hline ITU* recorrente & 3 & & \\
\hline & & 41 & 43,16 \\
\hline & Sim & 24 & 25,26 \\
\hline & Não & 30 & 31,58 \\
\hline
\end{tabular}

$\mathrm{N}$

95

*Infecção

do

trato

urinário

Fonte: Próprio autor

O tempo de internação das pacientes variou entre quatro a oito dias, com uma mediana de seis dias (Figura 1). 
Figura 1. Tempo de internação de gestantes em maternidade pública de baixo risco para tratamento de infecção do trato urinário. Curitiba-PR, Brasil, 2020

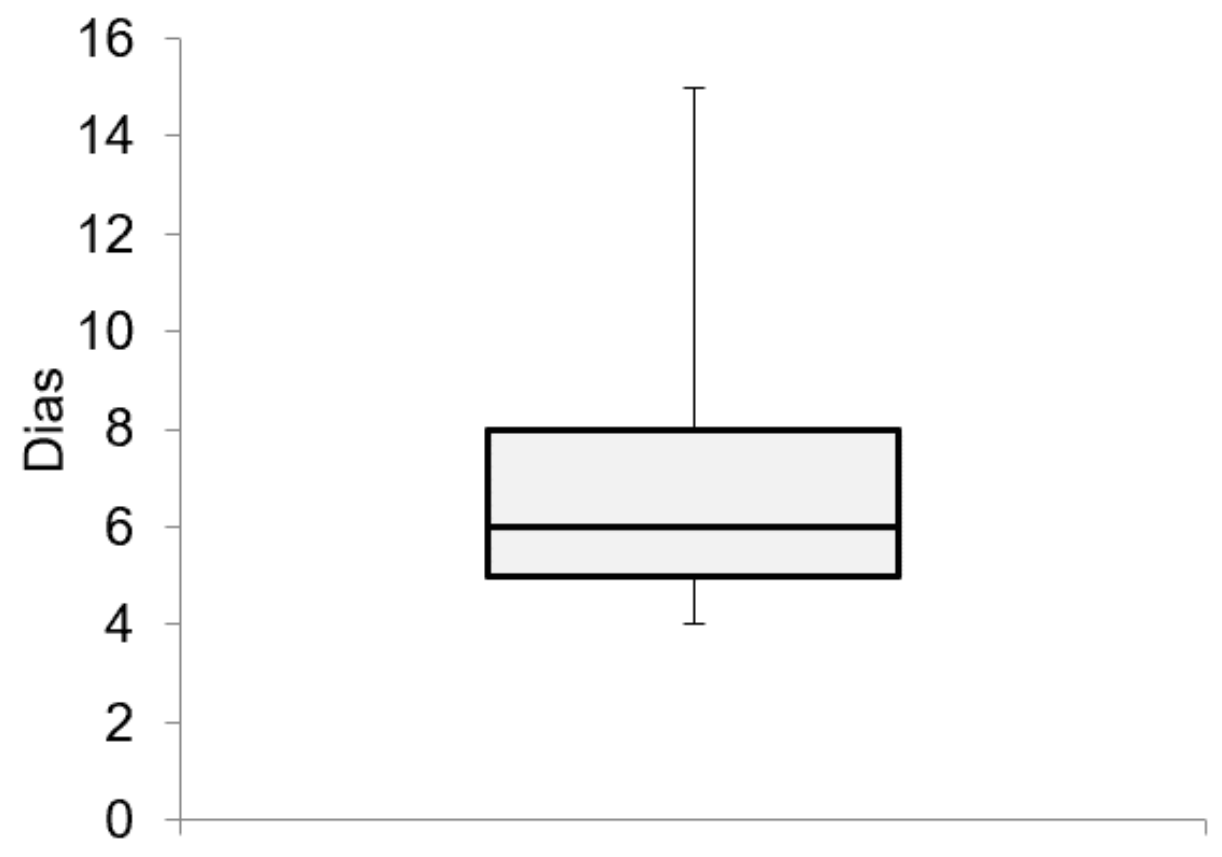

$N: 95$

Fonte: Próprio autor

O desfecho majoritário foi parto vaginal, seguido de parto cesáreo e pequena parcela de aborto. Alguns casos graves necessitaram de transferência para hospital de maior complexidade. Cerca de um quarto das gestantes não retornaram à maternidade, ficando o desfecho final inconclusivo por falta de informação (Figura 2). 
Figura 2. Desfecho clínico de gestantes internadas em maternidade pública de baixo risco para tratamento de infecção do trato urinário. Curitiba-PR, Brasil, 2020

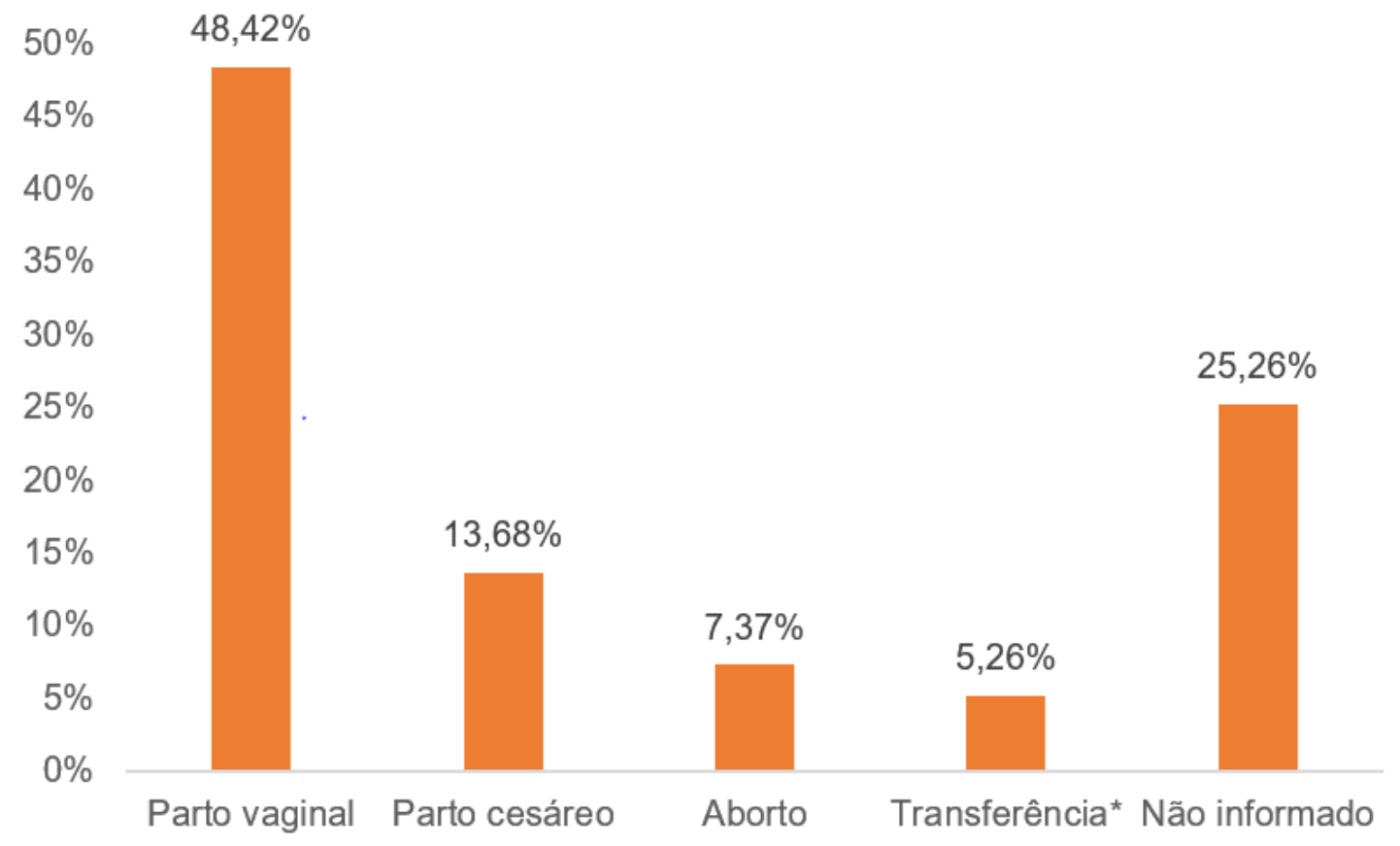

Notas: $N=95 ;{ }^{*}$ Transferência para hospital de maior complexidade Fonte: Próprio autor.

Foram realizadas 100 uroculturas nas pacientes internadas, com uma positividade acima de $70 \%$. Houve poucos casos de desenvolvimento de várias espécies bacterianas, o que indica provável contaminação por microbita genital, devido à falha no procedimento de coleta da urina (Figura 3). 
Figura 3. Resultado de cultura de urina em gestantes internadas em maternidade pública de baixo risco para tratamento de infecção urinária. Curitiba - PR, Brasil, 2020

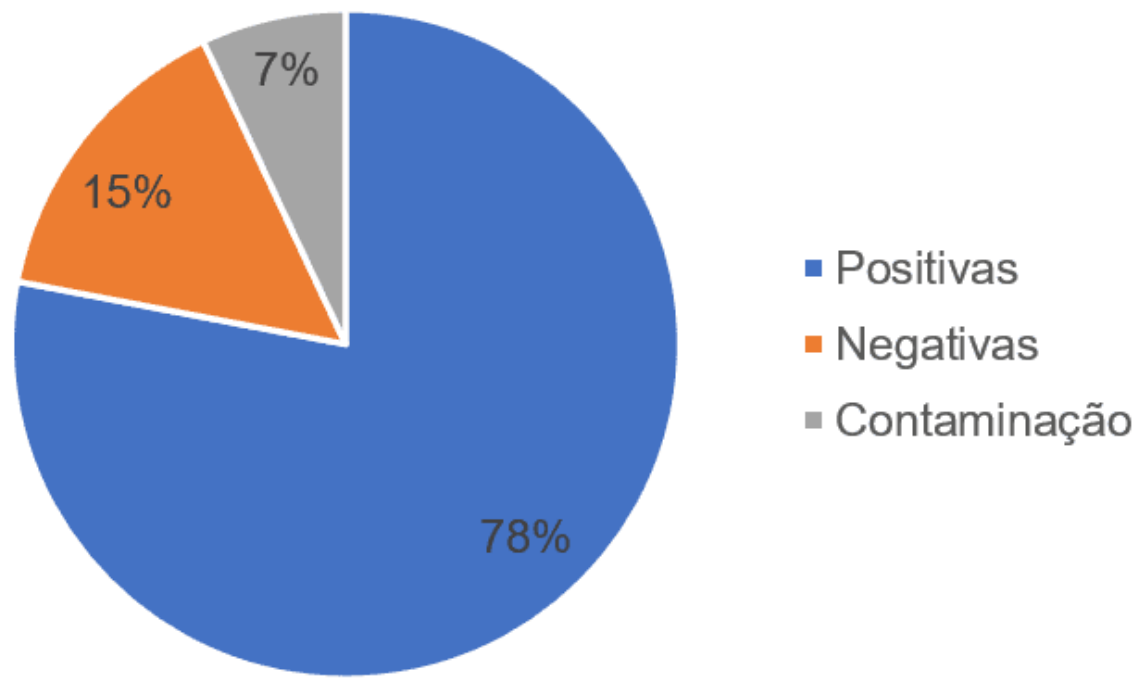

Nota: $N=100$

Fonte: Próprio autor.

Escherichia coli foi a bactéria predominante nas uroculturas, seguida de Proteus mirabilis, Staphylococcus saprophyticus, Streptococcus agalactiae, Klebsiella pneumoniae, Enterococcus faecalis e demais microrganismos (Tabela 3).

Tabela 3. Etiologia microbiana de infecção de trato urinário em gestantes internadas em maternidade pública de baixo risco. Curitiba - PR, Brasil, 2020

\begin{tabular}{|l|l|l|}
\hline Microrganismos & N & $\%$ \\
\hline Escherichia coli & 45 & 57,69 \\
\hline Proteus mirabilis & 8 & 10,26 \\
\hline Staphylococcus saprophyticus & 7 & 8,97 \\
\hline Streptococcus agalactiae & 5 & 6,41 \\
\hline Klebsiella pneumoniae & 4 & 5,13 \\
\hline Enterococcus faecalis & 3 & 3,85 \\
\hline Outros & 6 & 7,69 \\
\hline
\end{tabular}

RC: 100422

Link de acesso: https://www.nucleodoconhecimento.com.br/saude/caracteristicas-clinicas 


\section{DISCUSSÃO}

A redução da morbimortalidade materna e neonatal depende fundamentalmente de um processo de cuidado integral e fundamentado em políticas públicas que assegurem a saúde das mulheres e conceptos durante o todo o período de gestação, incluindo parto e puerpério. A conscientização da população como agente ativo no cuidado com a saúde leva a uma procura espontânea, não só para o tratamento de doenças, mas para ações de promoção e prevenção. Neste contexto, o estrato social, o nível educacional e o poder econômico da população são fatores determinantes para o acesso a serviços de saúde (BERQUÓ; LAGO, 2016).

O perfil das gestantes da maternidade desse estudo revelou o predomínio de mulheres no período reprodutivo entre 20 e 34 anos, com baixa e média escolaridade, raça branca. Cerca de $24 \%$ das pacientes se enquadravam na faixa etária da adolescência, entre 15 e 19 anos (Tabela 1). Os resultados da Pesquisa Nacional de Demografia e Saúde da Criança e da Mulher-2006 (PNDS-2006) apontam para um rejuvenescimento do processo reprodutivo, onde a fecundidade das mulheres mais jovens (15 a 19 anos) passou a representar $23 \%$ da taxa total, ao mesmo tempo em que revelam uma tendência de queda na taxa de fecundidade, a qual atingiu o seu menor índice de 1,8 filhos por mulher (MINISTÉRIO DA SAÚDE, 2009). A gravidez na adolescência por si só é considerada de alto risco, mas quando associada a agravos, como ITU, as complicações perinatais podem ser potencializadas. Políticas públicas de inclusão direcionadas para classes sociais mais vulneráveis, visando a promoção da qualidade de vida, através do aumento no nível de alfabetização, acesso ao mercado de trabalho e uso de métodos contraceptivos, são fundamentais para redução das taxas de gravidez na adolescência (ZERMIANI et al., 2018).

As taxas de escolaridade de $22 \%$ para ensino fundamental completo e $39 \%$ ensino médio completo estão acima da média reportada pelo Instituto Brasileiro de Geografia 
e Estatística (IBGE, 2019), com base na Pesquisa Nacional por Amostra de Domicílios Contínua (PNAD Contínua-2019), onde se verificou 8,0\% e 27,4\%, respectivamente, para as mesmas categorias (Tabela 1). Em relação ao ensino superior completo, esta taxa cai para apenas $2 \%$, evidenciando o afunilamento no acesso da população a este nível de escolaridade. Entretanto, na análise desse dado deve ser considerada a faixa etária de um quarto das gestantes participantes desse estudo, entre 15 e 19 anos, portanto sem tempo hábil de concluir o ensino superior. Estudos mostram uma taxa de fecundidade de quatro filhos para mulheres sem nenhum nível de instrução formal, enquanto fica abaixo de 1,6 para mulheres com escolaridade mínima de nove anos (LAGO, 2006). No presente estudo, praticamente metade das pacientes reporta paridade entre um e três filhos, porém não foi possível estabelecer a relação com o nível de escolaridade (Tabela 1). Conhecer esses indicadores é importante para o planejamento de políticas públicas destinadas a garantir a todas as mulheres condições igualitárias para regular sua fecundidade, de modo que haja menos discrepância entre as taxas de fertilidade observadas e as desejadas.

O predomínio da raça branca é o resultado esperado para a região geográfica. A grande maioria da população de Curitiba é originária de imigrantes europeus (alemães, italianos, poloneses, ucranianos), sendo a raça negra a minoria. Os fatores ambientais, socioeconômicos e as condições sanitárias são determinantes que impactam na qualidade de vida da população. Mais de $50 \%$ das mulheres atendidas na maternidade são provenientes de bairros e regiões periféricas afastadas do centro urbano, com problemas de infraestrutura e transporte, o que dificulta o acesso aos serviços de saúde. O mapeamento de procedência das gestantes por Distrito Sanitário revela muito sobre o contexto social no qual estão inseridas. Ações articuladas entre os líderes comunitários desses distritos e agentes de saúde são importantes para a construção de um modelo de conexão que permita o rastreamento das gestantes faltosas, ou que necessitem de readequação de conduta terapêutica, diminuindo, assim, o recorrente problema da perda de vínculo.

A Organização Mundial de Saúde estabelece que o pré-natal seja acompanhado por um mínimo de oito consultas, sendo mensais até a $28^{\mathrm{a}}$ semana, quinzenais da $28^{\mathrm{a}}$ a

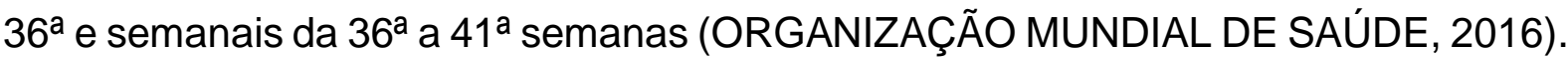
RC: 100422

Link de acesso: https://www.nucleodoconhecimento.com.br/saude/caracteristicas-clinicas 
Mais de $90 \%$ das mulheres encaminhadas para a maternidade estavam entre o $2^{\circ} \mathrm{e}$ 3 o trimestres de gestação, fato que gera um alerta quanto a necessidade de intensificação dos cuidados de atenção pré-natal neste período, visto que a presença de comorbidades, e em especial de ITU, está relacionada a partos prematuros e ruptura de membranas (DUARTE et al., 2008). É importante manter o contato constante com essas pacientes, através de busca ativa, estabelecendo uma rotina de vigilância que permita uma atuação pontual em caso de piora do estado clínico.

Um dado preocupante é que quase a metade das mulheres relatou ITU de repetição (43\%) (Tabela 2). Considera-se ITU de repetição a presença de dois ou mais episódios em seis meses ou três ou mais em um ano, após o tratamento com cura de cada episódio. Gestantes com ITU de repetição ou pielonefrite são classificadas de alto risco e muitas vezes demandam internação hospitalar para tratamento (MINISTÉRIO DA SAÚDE, 2012).

O desfecho esperado para uma gestante sem fatores de risco corresponde a uma média de permanência hospitalar em torno de 2,1 dias para parto vaginal e de 2,6 dias para parto cesáreo (ENTINGER; PINTO; GOMES, 2019). No caso dessas gestantes internadas para tratamento de ITU, a mediana de permanência hospitalar foi de aproximadamente seis dias, com extremos de até 15 dias (Figura 1). Além disso, mais de $50 \%$ das gestantes precisaram de mais de uma internação hospitalar e em torno de $5 \%$ apresentaram complicações que resultaram em transferência para hospital de maior complexidade (Tabela 2). Esses dados enfatizam a importância de se monitorar continuamente ITU em gestantes e intervir precocemente no sentido de se evitar ao máximo longos períodos de internação, que além de expor a paciente ao ambiente hospitalar, demanda gastos extras de recursos públicos.

O parto vaginal prevaleceu entre as gestantes com histórico de ITU, enquanto a taxa de cesarianas $(13,6 \%)$ foi inferior ao valor admitido pelo Ministério da Saúde, que estipula entre 25 e 30\% (MINISTÉRIO DA SAÚDE, 2016). Cerca de 25\% das gestantes atendidas primeiramente na maternidade não retornaram para 0 parto, impedindo um acompanhamento integral até o puerpério. Espera-se que com a elaboração de novos protocolos que contemplem ações integradas entre as equipes RC: 100422

Link de acesso: https://www.nucleodoconhecimento.com.br/saude/caracteristicas-clinicas 
da atenção primária, da atenção terciária e da comunidade, diminuam esses casos de perda de vínculo (Figura 2).

A bacteriúria assintomática é comumente detectada apenas ao nível laboratorial e tem o potencial de emergir como infecção sintomática (NICOLLE et al., 2019). A sua detecção precoce depende da realização de urocultura e pesquisa de elementos e sedimentos anormais em urina, exames extremamente importantes e que devem ser solicitados durante o seguimento trimestral da gestante. Nesta pesquisa, a maioria das pacientes triada para ITU apresentou urocultura positiva com desenvolvimento de somente uma espécie bacteriana, em contagem superior a $100.000 \mathrm{UFC/mL}$. Foram poucos os casos de urocultura negativa e contaminação (Figura 3). Considerando que uma parcela das pacientes relatou ter feito uso de antibiótico previamente, a presença de ITU não foi descartada com a urocultura negativa, prevalecendo o diagnóstico clínico baseado em outras evidências, como sinais e sintomas característicos, histórico de ITU anterior, exame parcial de urina alterado, hemograma com evidências de processo infeccioso e/ou exame de imagem sugestivo.

O espectro microbiano das ITU consistiu principalmente de Escherichia coli, com ocasional ocorrência de outras espécies bacterianas, como Proteus mirabilis. (Tabela 4). A presença de bacteriúria assintomática por Estreptococo do grupo B (GBS, Streptococcus agalactiae) pode sinalizar para uma microbiota vaginal com predomínio dessa bactéria, elevando o risco potencial para desenvolvimento de corioamnionite, endometrite, pneumonia, bacteremia e sepse puerperal (PUOPOLO; MADOFF; EICHENWALD, 2019). Após melhora clínica e laboratorial as pacientes receberam alta hospitalar, e quando pertinente, com orientação de continuação do antibiótico por via oral completando-se sete a 14 dias de tratamento conforme o caso. O controle de cura considerou urocultura negativa após sete dias do término do tratamento e quadro clínico favorável.

Além do histórico de ITU anterior e das alterações fisiológicas e anatômicas, condições socioeconômicas precárias também são consideradas como fatores de risco para bacteriúria na gestação, contribuindo para ocorrência do processo infeccioso (LEE, et al., 2020). Baixos índices de escolaridade comprometem o acesso RC: 100422 
à informação e a medidas de prevenção e promoção à saúde, impedindo as pessoas de atuarem como agentes ativos no autocuidado (RAMOS; CUMAN, 2009). Este estudo, ao relatar o contexto social e clínico das mulheres atendidas na maternidade, aponta para a necessidade de readequações de protocolos para promoção da saúde e prevenção de doenças que coloquem em risco a integridade materno fetal.

Para um acompanhamento de qualidade da gestante é necessária a implantação de um modelo de trabalho em rede, o qual firme parcerias entre a atenção primária e terciária, com compartilhamento de informações em tempo real, garantindo um atendimento integral e efetivo. Também é importante a elaboração de protocolos que contemplem o compartilhamento das responsabilidades com a gestante, dando-Ihe autonomia de escolha e poder de decisão. Assim, ao transformar a realidade da mulher, o empoderamento feminino desempenha uma parte importante na redução da morbimortalidade materno-infantil, levando a gestante a um engajamento ativo nos cuidados pré-natais.

\section{CONCLUSÃO}

Os resultados obtidos com esse estudo serão úteis para fundamentar outras pesquisas e para a elaboração de protocolos institucionais, com o intuito de monitorar as gestantes com ITU, desde a consulta inicial na Unidade Básica de Saúde até o desfecho final na maternidade, mapeando todos os principais fatores de risco. Como limitação para o estudo destaca-se a dificuldade para a coleta de dados, devido a incompletude de parte dos prontuários e falhas no sistema eletrônico de cadastro. Estas lacunas relacionadas às informações podem ser sanadas com a otimização do sistema de prontuário eletrônico e a integração dos profissionais desde o atendimento primário até o secundário, incluindo a gestante como protagonista do processo de cuidado.

\section{REFERÊNCIAS}

ALKEMA, Leontine, et al. Global, regional, and national levels and trends in maternal mortality between 1990 and 2015, with scenario-based projections to 2030: a 
systematic analysis by the UN Maternal Mortality Estimation Inter-Agency Group. Lancet, v. 387, n. 10017, p. 462 - 474, 2016. doi:10.1016/S0140-6736(15)00838-7.

BERQUÓ, Elza; LAGO, Tania di Giacomo do. Atenção em Saúde Reprodutiva no Brasil: eventuais diferenças étnico-raciais. Saúde Soc., v. 25, n. 3, p. 550-560, 2016. Disponível em: https://www.scielo.br/pdf/sausoc/v25n3/1984-0470-sausoc-25-0300550.pdf.

BLENCOWE, Hannah, et al. National, regional, and worldwide estimates of stillbirth rates in 2015, with trends from 2000: a systematic analysis. Lancet, v. 4, n. 2, p. E98 - E108, 2016. doi:10.1016/S2214-109X(15)00275-2.

BRASIL. Ministério da Saúde. Centro Brasileiro de Análise e Planejamento. Pesquisa Nacional de Demografia e Saúde da Criança e da Mulher (CEBRAP): PNDS 2006. Brasília, DF, 2009, 302 p.

BRASIL. Ministério da Saúde. Comissão Nacional de Incorporação de Tecnologias no SUS-CONITEC. Diretrizes de atenção à gestante: a operação cesariana. Brasília, DF, 2016, $106 \mathrm{p}$.

BRASIL. Ministério da Saúde. Secretaria de vigilância em saúde. Boletim Epidemiológico 20. Brasília, DF, Mai 2020, v. 51, 47 p.

BRASIL. Ministério da Saúde. Secretaria de Atenção à Saúde. Departamento de Ações Programáticas Estratégicas. Gestação de Alto Risco. Manual Técnico. 5ª ed. Área Técnica de Saúde da Mulher. Brasília, DF, 2012, 301 p.

Curitiba. Secretaria Municipal de Saúde (SMS). Pré-natal e puerpério na atenção primária. Curitiba, PR, 2020.151 p.

DUARTE, Geraldo, et al. Urinary tract infection in pregnancy. Rev. Bras. Ginecol. Obstet., v.30, n. 2, p. 93-100, 2008.

ENTINGER, Aline Piovezan; PINTO, Márcia Ferreira Teixeira; GOMES, Maria Auxiliadora de Souza. Análise de custos da atenção hospitalar ao parto vaginal e à RC: 100422

Link de acesso: https://www.nucleodoconhecimento.com.br/saude/caracteristicas-clinicas 
cesariana eletiva para gestantes de risco habitual no Sistema Único de Saúde. Ciênc. Saúde Coletiva, v. 24, n. 4, p.1527-1536, 2019. https://doi.org/10.1590/141381232018244.06962017.

FRANCESCO, Maria Antonia de, et al. Urinary tract infections in Brescia, Italy: Etiology of uropathogens and antimicrobial resistance of common uropathogens. Med. Sci. Monit., v. 13, n. 6, p. 136-144, 2007.

GUPTA, Kalpana, et al. International clinical practice guidelines for the treatment of acute uncomplicated cystitis and pyelonephritis in women: A 2010 update by the Infectious Diseases Society of America and the European Society for Microbiology and Infectious Diseases. Clin. Infect. Dis., v. 52, n. 5, p. e103-120, Mar 2011.doi: 10.1093/cid/ciq257.

HOOTON, Thomas M.; GUPTA, Kalpana. Acute complicated urinary tract infection (including pyelonephritis) in adults. In: Calderwood, S. B.; Bloom, A., (Ed), UpToDate, 2019a. Disponível em: <http://www.uotodate.com/online>. Acesso em 15/01/2021.

HOOTON, Thomas M.; GUPTA, Kalpana. Acute simple cystitis in women. In: Calderwood, S, B.; Bloom, A., (Ed), UpToDate, 2019b. Disponível em: <http://www.uotodate.com/online>. Acesso em 15/01/2021.

Instituto de Geografia e Estatística (IBGE). Pesquisa Nacional por Amostra de Domicílios Contínua. Educação 2019. Rio de Janeiro, 2019, 16 p. Disponível em: https://biblioteca.ibge.gov.br/visualizacao/livros/liv101736_informativo.pdf. Acesso em 02/11/2020.

LAGO, Tania Di Giacomo do. Nascimentos não planejados no Brasil eram 46\% em 2006. Diminuíram? Rev. Bras. Estud. Popul., v. 32, n. 2, p. 387-394, 2015. https://doi.org/10.1590/S0102-30982015000000022.

LEE, Anne CC, et al. Urinary tract infections in pregnancy in a rural population of Bangladesh: population-based prevalence, risk factors, etiology, and antibiotic 
resistance. BMC Pregnancy Childbirth., v. 20, n. 1, 2020, 11p. https://doi.org/10.1186/s12884-019-2665-0.

MOORE, Ainsley, et al. Canadian task force on preventive health care. Recommendations on screening for asymptomatic bacteriuria in pregnancy. CMAJ, v. 190, n. 27, p. E823-E830, Jul 2018. doi: 10.1503/cmaj.171325.

NICOLLE, Lindsay E., et al. Clinical Practice Guideline for the Management of Asymptomatic Bacteriuria: 2019. Update by the Infectious Diseases Society of America. Clin. Infect. Dis., v. 68, n. 10, p. E83-E75, 2019. https://doi.org/10.1093/cid/ciy1121.

Organização das Nações Unidas (ONU). UN General Assembly. United Nations Millennium Declaration, Resolution Adopted by the General Assembly; Sep 2000. Disponível em: https://www.who.int/topics/millennium_development_goals/maternal_health/en/). Acesso em 15/02/2021.

Organização Mundial de Saúde (OMS). Recomendações da OMS sobre cuidados pré-natais para uma experiência positiva na gravidez. Geneva, 2016, 10 p. Disponível em: https://apps.who.int/iris/bitstream/handle/10665/250800/WHORHR16.12por.pdf;jsessionid=27DFA5E7EFD0582097C9E82DB5CE8904?sequence =2. Acesso em 10/01/2021.

Organização Pan-Americana de Saúde. Folha informativa. Mortalidade materna. Brasília, DF, Ago 2018.2 Disponível em: https://www.paho.org/bra/index.php?option=com_content\&view=article\&id=5741:folh a-informativa-mortalidade-materna\&ltemid=820. Acesso em 17/02/2021.

OUD, Lavi. Pregnancy-Associated Severe Sepsis: Contemporary State and Future Challenges. Infect. Dis. Ther., v. 3, n. 2, p. 175 - 189, 2014. doi: 10.1007/s40121014-0037-7. 
PETERSSON, Christine, et al. Suppressed antibody and interleukin-6 responses to acute pyelonephritis in pregnancy. Kidney Int., v. 45, n. 2, p. 571-577, Feb 1994. doi: 10.1038/ki.1994.74.

PFITSCHER, L.C., et al. The role of infection and sepsis in the Brazilian Network for Surveillance of Severe Maternal Morbidity. Trop. Med. Int. Health, v. 21, p. 183-193, 2016. https://doi.org/10.1111/tmi.12633

PUOPOLO, Karen M.; MADOFF, Laurence C; EICHENWALD, Eric C. Early-onset group B streptococcal disease in the era of maternal screening. Pediatrics, v. 115, n. 5, p. 1240-1246, May 2005. doi: 10.1542/peds.2004-2275.

RAMOS, Helena Ângela de Camargo, CUMAN, Roberto Kenji Nakamura. Fatores de risco para prematuridade: Pesquisa documental. Esc. Anna Nery Rer. Enferm., v. 13, n. 2, p. 297-304, 2009.

SAY, Lale, et al. Global causes of maternal death. A WHO systematic analysis. Lancet, v. 2, n. 6, p. E323-E333, Jun 2014.

SMAILL, FM; VASQUEZ, JC. Antibiotics for asymptomatic bacteriuria in pregnancy. Cochrane Systematic Review - Intervention. In: The Cochrane Database of Systematic Reviews. Hoboken (NJ), 2015, 50 p. Disponível em: <https://doi.org/10.1002/14651858.CD000490.pub3.>. Acesso em 11/01/2020.

ZERMIANI, Thabata Cristy, et al. A relação entre indicadores de desenvolvimento humano e de saúde materna nos municípios da Região Metropolitana de Curitiba PR. Cad. Saúde Colet., v. 26, n. 1, p. 100 - 106, 2018.

Enviado: Fevereiro, 2021.

Aprovado: Novembro, 2021. 